Original Research Article

\title{
A survey to assess awareness about fixed dose combinations (FDCs) among pharmacists in two Central Kashmir Districts, Srinagar and Budgam, Kashmir, India
}

\author{
Shakeel Ahmad Mir*
}

\begin{abstract}
Department of Clinical Pharmacology, Sher-I-Kashmir Institute of Medical Sciences, Srinagar, Kashmir, India
\end{abstract}

Received: 17 February 2017 Accepted: 28 March 2017

*Correspondence to: Dr. Shakeel Ahmad Mir, Email:

drshakeelahmadmir@gmail.com

Copyright: $\odot$ the author(s), publisher and licensee Medip Academy. This is an openaccess article distributed under the terms of the Creative Commons Attribution NonCommercial License, which permits unrestricted noncommercial use, distribution, and reproduction in any medium, provided the original work is properly cited.

\begin{abstract}
Background: FDCs are highly popular in Indian pharmaceutical market. The FDCs have both advantages as well as disadvantages. To be advantageous WHO guidelines for the manufacture and use of FDCs must be strictly followed. Irrational use of FDCs is a major public health problem and leads to increased risk of adverse drug events, higher treatment costs and antimicrobial resistance. FDCs as well as other single component drugs cannot be used rationally unless everyone involved directly or indirectly in the health care profession is involved. Pharmacist is a coordinator between different members of healthcare team and the patients. Hence, his role in safe use of medicines is important. The present study was undertaken to assess the knowledge of pharmacists about FDCs.
\end{abstract}

Methods: A descriptive questionnaire survey was conducted in various government and private pharmacies of two Central Kashmir Districts, Srinagar and Budgam, aiming to assess the knowledge of pharmacists about FDCs. The questionnaires were distributed randomly among 79 pharmacists, out of which 60 returned the completed questionnaire.

Results: $55.00 \%$ of the respondents knew the basic facts about FDCs. 96.66\% knew that FDCs reduced the cost of therapy and $93.33 \%$ were aware that FDCs improve patient compliance. $60 \%$ answered incorrectly when asked about effect of FDCs on cumulative toxicity. Almost equal percentage $(63.33 \%)$ answered incorrectly when asked about rationality and ADR profile of FDCs. 83.33\% knew that it is difficult to know the offending agent in case ADRs occur after FDC use.78.33\% respondents thought that all FDCs are approved by drug regulatory authorities.

Conclusions: The study showed that pharmacists had not the enough knowledge about FDCs. Pharmacy students in their formative years of learning should be taught to promote rational use of FDCs as they are the future custodians of technical information on the products available on their domestic market.

Keywords: Drug, Fixed dose combination, Pharmacist

\section{INTRODUCTION}

Fixed dose combination (FDC) is a combination of two or more actives in a fixed ratio of doses. This term is used generically to mean particular combination of actives irrespective of the formulation or brand. It may be administered as single entity products given concurrently or a finished pharmaceutical product. ${ }^{1}$ A new FDC is considered as "New Drug" according to Drugs and Cosmetics Act, 1940; hence it must undergo clinical trials before entering the market. ${ }^{2}$
The FDCs are highly popular in the Indian pharmaceutical market. The rationality of FDCs should be based on certain aspects such as: the drugs in combination should act by different mechanisms, the pharmacokinetics must not be widely different, and the combination should not have supra-additive toxicity of the ingredients. ${ }^{3}$

FDCs have advantages when there is an identifiable patient population for whom treatment with a particular combination of actives in a fixed ratio of doses has been shown to be safe and effective, and when all of the 
actives contribute to the overall therapeutic effect. In addition, there can be real clinical benefits in the form of increased efficacy and/or a reduced incidence of adverse effects, but such claims should be supported by evidence. $^{4}$

The rationality of FDCs is one of the most controversial and debatable issues. The FDCs can be divided into rational or irrational. ${ }^{5}$

Rational drug use is conventionally defined as "patients receive medication appropriate to their clinical needs, in doses that meet their requirements, for an adequate period of time, and at the lowest cost to them and their community. ${ }^{6}$

The trend of prescribing FDCs is increasing in clinical practice. Irrational prescribing of FDCs leads to increased risk of adverse drug reactions, higher treatment cost, emergence of resistant organisms and sometimes treatment failure. ${ }^{7}$

Government-employed pharmacists are responsible for drug management which includes the selection of essential drugs, the determination of drug requirements, the procurement and distribution of drugs and their rational use, as well as the design and use of information systems. Also, they collect and collate data required by their national government agencies and by international bodies. Pharmacists are a vital member of healthcare team. They are the custodians of much technical information on the products available on their domestic market. Pharmacists individually and as a profession has important roles to play in positively influencing drug use as well as other aspects of healthcare. ${ }^{8}$

The amount of medical knowledge has grown substantially over the last few decades. It is important for the pharmacists to keep current on new literature to address a variety of drug information requests. ${ }^{9}$

There is a lack of awareness among patient, pharmacist and physician about FDCs. ${ }^{10}$

The present study was undertaken keeping in view the increasing tendency to prescribe FDCs and vital role of pharmacists to ensure their rational use.

\section{METHODS}

\section{Study design}

We conducted a questionnaire based survey of pharmacists to assess their current knowledge about Fixed Dose Combinations (FDCs).

\section{Study population}

A total of 79 pharmacists were given the questionnaire out of which 60 returned the completed questionnaire, giving a response rate of $75.94 \%$. The study was conducted from April 2016 to June 2016 in various government health centers and private pharmacies run by trained pharmacists in two Central Kashmir districts, Srinagar and Budgam. A written informed consent was taken. Participants were informed about the objectives of the study and were assured that their response shall be anonymous. The participation was voluntary and without compensation. During the study, declaration of Helsinki guidelines was followed.

\section{Questionnaire}

The Structured questionnaire used in this study was created by reviewing relevant literature and questionnaires used previously in similar studies. ${ }^{10}$ The questionnaire was pretested for the content and design on ten pharmacists to clarify any ambiguities and suitable modifications were done. The final version of the questionnaire was used in this study.

\section{Data analysis}

Analysis was done by combination of manual calculators and Vassar Stats. Analysis was carried out using descriptive statistics at $95 \%$ confidence intervals. Results were expressed in frequencies and percentages.

\section{RESULTS}

Table 1 shows that most of the participants (90\%) were male. $78.33 \%$ had done diploma pharmacy either from government run training intuitions or private pharmacy schools. $61.66 \%$ were working in private sector, either running their own medical shops or working in private nursing homes.

Table 1: Demographics.

\begin{tabular}{|ll|}
\hline Variables & No. $(\%)$ \\
\hline Sex & \\
\hline Males & $54(90 \%)$ \\
\hline Females & $06(10 \%)$ \\
\hline Qualification & \\
\hline M. Pharma & $01(1.66 \%)$ \\
\hline B. Pharma & $12(20.00 \%)$ \\
\hline Diploma Pharmacy & $47(78.33 \%)$ \\
\hline Nature of job & \\
\hline Government sector & $23(38.33 \%)$ \\
\hline Private Sector & $37(61.66 \%)$ \\
\hline
\end{tabular}

Table 2 Shows that $55.00 \%$ of the respondents knew the basic facts about FDCs. 96.66\% knew that FDCs reduced the cost of therapy and $93.33 \%$ were aware that FDCs improve patient compliance.60\% answered incorrectly when asked about effect of FDCs on cumulative toxicity. Almost equal percentage (63.33\%) answered incorrectly when asked about rationality and ADR profile of FDCs. $83.33 \%$ knew that it is difficult to know the offending 
agent in case ADRs occur after FDC use.78.33\% respondents thought that all FDCs are approved by drug regulatory authorities. $61.66 \%$ knew that Government of India banned 344 FDCs in March 2016.

Table 2: Responses.

\begin{tabular}{|lll|}
\hline Question & Correct answer & Incorrect answer \\
\hline $\begin{array}{ll}\text { FDC means fixed drug combination or fixed dose combination } \\
\text { FDCs reduce cost of therapy }\end{array}$ & $26(43.33 \%)$ & $34(56.66 \%)$ \\
\hline $\begin{array}{l}\text { Benefits of FDCs are patient convenience and improved } \\
\text { Compliance }\end{array}$ & $56(93.33 \%)$ & $4(6.66 \%)$ \\
\hline $\begin{array}{l}\text { FDCs can help reduce cumulative toxicity } \\
\text { FDCs may result in enhanced adverse effects }\end{array}$ & $24(40 \%)$ & $36(60 \%)$ \\
\hline All FDCs available in the market are rational combinations & $22(36.66 \%)$ & $38(63.33 \%)$ \\
\hline $\begin{array}{l}\text { Does any FDC feature in the National List of Essential Medicines (NELM) of } \\
\text { India }\end{array}$ & $10(16.66 \%)$ & $50(83.33 \%)$ \\
\hline $\begin{array}{l}\text { Disadvantages of FDCs may be use of sub therapeutic doses of individual } \\
\text { drugs and difficulty in dose adjustment. }\end{array}$ & $28(46.66 \%)$ & $32(53.33 \%)$ \\
\hline $\begin{array}{l}\text { When each component of fixed combination has several possible dosages, } \\
\text { dosages that have shown benefit on hard clinical outcomes may be preferable } \\
\text { for the fixed combination }\end{array}$ & $10(16.66 \%)$ & $50(83.33 \%)$ \\
\hline $\begin{array}{l}\text { FDCs, in principle, may not be considered rational if the duration of action of } \\
\text { the component differ significantly }\end{array}$ & $39(65.00 \%)$ & $21(35.00 \%)$ \\
\hline $\begin{array}{l}\text { FDCs make it more difficult to determine the offending agent, if the patient } \\
\text { experiences an adverse event }\end{array}$ & $50(83.33)$ & $10(16.66 \%)$ \\
\hline $\begin{array}{l}\text { All FDcs in the market are approved by regulatory authority } \\
\text { No. of FDCs banned in India in 2016 }\end{array}$ & $47(78.33 \%)$ & $13(21.66 \%)$ \\
\hline \begin{tabular}{l} 
Average \\
\hline
\end{tabular} & $37(61.66 \%)$ & $23(38.33 \%)$ \\
\hline
\end{tabular}

\section{DISCUSSION}

As a principle, single medicines are to be preferred. FDCs are to be prescribed, only if the combination is rational and has a proven advantage with respect to therapeutic effect, safety and compliance or decreases the emergence of resistance. Some examples are diseases such as malaria, HIV infections, tuberculosis, where the emergence of antimicrobial resistance is an important issue.

The most pressing concern with irrational FDCs is that they expose patients to unnecessary risk of adverse drug reactions. Irrational FDCs also impose unnecessary financial burden on consumers. ${ }^{3}$

There is a growing concern over the irrational use of FDCs. Awareness about FDCs is most important to reduce the occurrence of possible adverse effects.

The knowledge possessed by a community is indicative of their understanding of the given subject. A study of knowledge, attitude and practice is the most important tool to assess the benefits and lacunae about a subject in the community, so that effective steps can be taken in that direction to improve the outcome.
Irrational prescribing of FDCs leads to increased risk of adverse drug reactions, higher treatment cost, emergence of resistant organisms and sometimes treatment failure.

A large number of FDCs are manufactured every year hence knowledge about FDCs is becoming increasingly important.

Knowledge about FDCs assumes a special significance among pharmacists as they are vital members of healthcare team. WHO recommends that governments and other regulatory authorities should give priority to the provision of equipment and learning material commensurate with the satisfactory pharmaceutical education. Being a vital member of healthcare providing system pharmacist's skills and knowledge in this regard are decisive. ${ }^{8}$

The present study revealed that the community pharmacists had an average knowledge about the rationale behind FDCs and guidelines for prescribing them. Although a majority (55\%) of the respondents answered various questions on FDCs correctly, but $45 \%$ were not fully aware about the basic facts about FDCs. The pharmacists are coordinators between different members of healthcare team as well as the patients. They can play a key role in promotion of rational use of drugs because they have a technical knowledge about types of 
drugs and have been taught basics of drug use during their training. By having access to medicinal records, they can influence the proper drug selection. Pharmacists need to be targeted repeatedly during their training and be taught basic facts about drugs as well as benefits as well as disadvantages of FDCs. As recommended by W.H.O appropriate actions should be taken to provide pharmacists with the requisite pharmaceutical care skills by continuously reviewing undergraduate or university curriculum outcomes, content and process to ensure that they are in line with the concept of pharmaceutical care so that they are able to provide basic pharmaceutical care to the patients.

\section{Limitations}

The present study is exploratory in nature and was conducted on regional level. It provides a basis for future multi-center confirmatory studies at national level with larger sample size.

\section{CONCLUSION}

Thousands of FDCs are available in India. The pharmacological rationale of some combinations has been questioned by various authorities. There is a growing concern about the irrational use of FDCs. Inappropriate or excessive use of FDCs may lead to severe adverse reactions, entail financial burden and promote drug resistant strains. There is lack of awareness among community pharmacists about FDCs. Awareness and education about irrational FDCs, combinations containing banned or controversial ingredients will help to minimize their misuse. The study findings highlight the urgent need for special education programs to educate the community pharmacists about the advantages and disadvantages of FDCs. Further studies at the national level in this regard are required.

Funding: No funding sources Conflict of interest: None declared

Ethical approval: The study was approved by the Institutional Ethics Committee

\section{REFERENCES}

1. WHO technical report series: WHO expert committee on specifications for pharmaceutical preparations; 2015.

2. Prakash S. Irrational combinations: No consideration for patient safety. Indian J Pharmacol. 2007;39:217.

3. Chandler S. Gautam and Lekha Saha Fixed dose drug combinations (FDCs): rational or irrational: a view point. Br J Clin Pharmacol. 2008;65(5):795-6.

4. WHO technical report series: Guidelines for registration of fixed-dose combination medicinal products; 2005.

5. Chandel S, Joshi A, Sonawane R, Jain N. A Brief Review on Rational Consideration of Fixed Dose Combinations. IJSR 2014;3(6):307-9.

6. Balasubramaniam R. A Study on Evaluation of Rationality of Fixed Dose Combinations. Am. J. PharmTech Res. 2013;3(5):538-47.

7. Goswami N, Gandhi A, Patel P, Dikshit R. An evaluation of knowledge, attitude and practices about prescribing fixed dose combinations among resident doctors. Perspect Clin Res. 2013;4:130-5.

8. The role of the pharmacist in the healthcare system.Report of a WHO consultative group, New Delhi India 13-16 December,1988.Report of a WHO meeting Tokyo Japan; 1993.

9. Ghaibi S., Ipema H., Gabay M. ASHP guidelines on the pharmacist's role in providing drug information. Am J Health-Syst Pharm. 2015;72:573-7.

10. Atal S, Phadnis P, Gudsurkar G. A study to assess and increase awareness regarding fixed dose combinations among medical undergraduates at Indore and Sagar, Madhya Pradesh, India. Int J Basic Clin Pharmacol. 2016;5:300-6.

Cite this article as: Mir SA. A survey to assess awareness about fixed dose combinations (FDCs) among pharmacists in two Central Kashmir Districts, Srinagar and Budgam, Kashmir, India. Int J Basic Clin Pharmacol 2017;6:1133-6. 